\title{
GÊNERO E RELIGIÃO: DISPUTAS POLÍTICAS NA CONSTRUCÃO DO PLANO MUNICIPAL DE EDUCAÇÃOO DE CHAPECÓ/SC
}

\author{
GENERO Y RELIGIÓN: DISPUTAS POLÍTICAS EN LA CONSTRUCIÓN DEL PLAN \\ MUNICIPAL DE EDUCACIÓN DE CHAPECÓ/SC
}
GENDER AND RELIGION: POLITICAL DISPUTES IN THE CONSTRUCTION OF THE MUNICIPAL EDUCATION PLAN IN CHAPECÓ/SC

Myriam Aldana Vargas Santin*

(iD) https://orcid.org/oooo-0oo2-2330-1557

Daian Cattani**

https://orcid.org/oooo-ooo3-1050-5443

Elcio Cecchetti***

https://orcid.org/oooo-0oo2-0946-320X

REVISTA PEDAGÓGICA

Revista do Programa de Pós-graduação em Educação da Unochapecó | ISSN 1984-1566 Universidade Comunitária da Região de Chapecó | Chapecó-SC, Brasil Como referenciar este artigo: SANTIN, M. A. V.; CATTANI, D.; CECCHETTI, E. Gênero e religião: disputas políticas na construção do plano municipal de educação de Chapecó/SC. Revista Pedagógica, Chapecó, v. 21, p. 306-320, 2019. DOI: http://dx.doi.org/10.22196/rp.v22io.5261

RESUMO: Neste trabalho objetivamos narrar e analisar as disputas políticas travadas entre gênero e religião a partir da denominada "ideologia de gểnero" na discussão da proposta do Plano Municipal de Educação (PME) de Chapecó/SC. Para isso, apresentamos algumas razões pelas quais os defensores da "ideologia de gênero" defendem seus posicionamentos relativos as questões de gênero e orientação sexual qualificando estes conceitos como algo destrutivos para a ordem estabelecida. Neste embate foi possível identificar as tensas relações entre gênero e religião no contexto do Estado laico e na incessante busca pela promoção dos direitos humanos. A partir de uma abordagem qualitativa, combinamos pesquisa do tipo bibliográfico com a observacão in loco da audiência pública realizada pela Câmara Municipal de Chapecó para debater o PME. Por fim, destacamos a complexidade que estes temas tem atualmente na sociedade, onde diversos grupos travam uma batalha político-ideológica a respeito desta questão, e indicamos que é imprescindível a criação de políticas de combate à violência e a desigualdade de gênero, inclusive no espaço escolar.

Palavras-chave: Gênero; Religião; Plano municipal de educação; Ideologia de gênero; Estado laico.

RESUMEN: En este artículo pretendemos narrar y analizar las disputas políticas entre género y religión basadas en la llamada “ideología de género" en la discusión de la propuesta del Plan de Municipal de Educación (PME) de Chapecó/SC. Con este fin, presentamos algunas razones por las cuales los defensores de la "ideología de género" defienden sus posiciones sobre cuestiones de género y orientación sexual al describir estos conceptos como destructivos para el orden establecido. En este embate fue posible identificar las tensas relaciones entre género y religión en el contexto del estado laico y de la búsqueda incesante de la promoción de los derechos humanos. Desde un enfoque cualitativo, combinamos la investigación bibliográfica con la observación in loco de la audiencia pública celebrada por el Ayuntamiento de Chapecó para debatir sobre el PME. Finalmente, destacamos la complejidad que estos temas tienen actualmente en la sociedad, donde varios grupos están estrellando una batalla político-ideológica sobre este tema, e indicamos que es esencial crear políticas para combatir la violencia y la desigualdad de género, incluso en el espacio de la escuela.

Palabras-clave: Género; religión; Plan municipal de educación; Ideología de género; Estado laico.

ABSTRACT: In this paper we aim to narrate and analyze
the political disputes between gender and religion based
on the so-called "gender ideology" in the discussion of the
Municipal Education Plan (PME) proposal in Chapecó.
To this end, we present some reasons why advocates of
"gender ideology" defend their positions on gender issues
and sexual orientation by describing these concepts as
destructive to the established order. In this sense, it was
possible to identify the tense relations between gender
and religion in the context of the secular state and the
incessant search for the promotion of human rights.
From a qualitative approach, we combine bibliographic
research with the on-site observation of the public
hearing held by Chapecó City Council to debate the PME.
Finally, we highlight the complexity that these themes
currently have in society, where several groups are
waging a political-ideological battle on this issue, and we
indicate that it is essential to create policies to combat
violence and gender including the school space.

Keywords: Gender; Religion; Municipal education plan; Gender ideology; Secular State 


\section{Introdução}

No início de 2009, o Ministério da Educação (MEC), com apoio de diversas instituições do campo educacional, deu início ao movimento que culminou na Conferência Nacional de Educação (CONAE), realizada em Brasília, no ano seguinte. Organizada inicialmente em etapas municipais, regionais e estaduais, em diferentes territórios e espaços institucionais, estudantes, pais, profissionais da educação, gestores, agentes públicos e sociedade civil tiveram a oportunidade de discutir os rumos da educação brasileira ${ }^{1}$.

O resultado desse processo de mobilização ficou consolidado na aprovação de um Documento Final (BRASIL, 2010a) que apresentou diretrizes, metas e ações para a política nacional de educação, na perspectiva da inclusão, igualdade e diversidade, constituindo um marco histórico para a educação brasileira na contemporaneidade. No referido documento, o termo "gênero" é mencionado 46 vezes e "diversidade sexual" é aludido em outras 44 citações.

Especificamente, o Eixo VI - Justiça Social, Educação e Trabalho: inclusão, diversidade e igualdade, acolheu diversas propostas visando superar a discriminação de gênero e assegurar a educação para orientação sexual na escola. De acordo com o documento, a discussão de gênero e diversidade sexual deve fazer parte da política de valorização e formação inicial e continuada dos professores e ser inserida no Programa Nacional do Livro Didático (PNLD), nos currículos das licenciaturas e da educação básica, dentre outras recomendações.

Com base nos resultados da CONAE 2010, o MEC elaborou a primeira proposta do Plano Nacional de Educação (PNE), elencando um conjunto de 20 metas com inúmeras estratégias com vistas a orientar as políticas educacionais no país para a década de 2011-2020. Na proposição inicial, o tema "gênero" e "orientação sexual" constavam apenas na estratégia 3.9, a saber: "Implementar políticas de prevenção à evasão motivada por preconceito e discriminação à orientação sexual ou à identidade de gênero, criando rede de proteção contra formas associadas de exclusão" (BRASIL, 2010b, p. 7).

No Congresso Nacional, o PNE demorou cerca de quatros anos para ser analisado e finalmente aprovado. $\mathrm{O}$ passo a passo do Plano no legislativo foi objeto de análise de vários trabalhos, tais como o de Brito (2015). A autora destaca que, dentre outros temas, o debate em torno da superação da discriminação por gênero e orientação sexual foi muito forte. $\mathrm{O}$ texto inicialmente aprovado pela Câmara dos Deputados, em 2012, definia que a superação das desigualdades educacionais requeria a "promoção da igualdade racial, regional, de gênero e de orientação sexual". No entanto, no Senado foram suprimidas tais expressões, e a redação final fixou genericamente a "promoção da cidadania e a erradicação de todas as formas de discriminação". $O$ texto proposto pelo relator foi apoiado por grupos religio-

\begin{abstract}
*Doutora Interdisciplinar em Ciências Humanas pela Universidade Federal de Santa Catarina. Professora titular da Universidade Comunitária da Região de Chapecó (Unochapecó). Líder do grupo Fogueira: Grupo de Estudos e Pesquisas de Gênero (Unochapecó).

E-mail:aldana@unochapeco.edu.br

**Graduado em Psicologia pela Universidade Comunitária da Região de Chapecó (Unochapecó) e graduado em Administração pelas Faculdades de Ciências Sociais Aplicadas. Membro do grupo Fogueira: Grupo de Estudos e Pesquisas de Gênero (Unochapecó).

E-mail: daiancattani@unochapeco.edu.br
\end{abstract}

\begin{abstract}
***Doutor em Educação pela Universidade Federal de Santa Catarina (UFSC). Docente do Mestrado em Educação da Universidade Comunitária da Região de Chapecó (Unochapecó). Vice-líder do Grupo de Pesquisa Ethos, Alteridade e Desenvolvimento (GPEAD/FURB) e do Grupo de Pesquisa Desigualdades Sociais, Diversidades Socioculturais e Práticas Educativas (Unochapecó).

E-mail: elcio.educ@hotmail.com
\end{abstract}

1 A CONAE mobilizou cerca de 3,5 milhões de brasileiros e brasileiras, contando com a participação de $450 \mathrm{mil}$ delegados e delegadas nas etapas municipal, intermunicipal, estadual e nacional, envolvendo, em torno de $2 \%$ da população do País. Essas vozes se fizeram representadas por meio dos delegados eleitos em seus estados, presentes na etapa nacional (BRASIL, 2010a). 
sos de diferentes denominações, mas criticado por defensores dos direitos humanos e da diversidade sexual.

Como houve alteração do texto original, o Projeto de Lei do PNE voltou para a Câmara e lá, novamente, o seu relator, deputado Ângelo Vanhoni (PT-PR), reinseriu o trecho suprimido, gerando uma série de debates. Deputados federais conservadores, ligados a grupos religiosos, entendiam que a ênfase na "[...] igualdade de gênero e orientação sexual permitiria a adoção de materiais didáticos e atividades escolares que incentivassem a homossexualidade, obrigando as crianças e jovens a naturalizarem aquilo que na concepção deles é antinatural" (CAVALCANTI et al, 2017, p. 19).

Em meio a uma cruzada político-discursiva contra a "ideologia de gênero", o PNE foi finalmente aprovado em 2014 com a retirada da terceira Diretriz (art. $2^{\circ}$, III), bem como de outras partes do seu texto que faziam qualquer menção a gênero, orientação sexual, identidade de gênero ou diversidade sexual. Assim, dentre as diretrizes do PNE, as que tratam da superação da discriminação (inciso III, art. $2^{\circ}$ ) e da promoção da diversidade (inciso X, art. $2^{\circ}$ ) ficaram de forma bem genérica (BRASIL, 2014a).

Por conseguinte, como ficou estabelecido no próprio PNE, os estados, o distrito federal e os municípios deveriam elaborar seus correspondentes planos de educação em consonância com as diretrizes, metas e estratégias previstas no documento nacional, no prazo de um ano (Art. 8, BRASIL, 2014a). Assim, para os grupos que lutaram pela retirada do termo "gênero" e "orientação sexual" no documento nacional, todos os demais planos da esfera estadual e municipal deveriam evitar qualquer menção às referidas temáticas.

Ocorre que, entre o período de 19 a 23 de novembro de 2014, o Fórum Nacional de Educação (FNE), órgão do Poder Executivo Federal, criado pela CONAE- 2010, estabelecido no Art. 6 do próprio PNE, realizou com o apoio do MEC e de diversas instituições, a $2^{\text {a }}$ Conferência Nacional de Educação (CONAE-2014).

O documento final desta Conferência (BRASIL, 2014b) deixou explícita a necessidade de superação das desigualdades educacionais, com ênfase na promoção da igualdade racial, regional, de "gênero e de orientação sexual”. Esse princípio se desdobrou em várias menções em todo o texto, como, por exemplo, "garantir condições institucionais que assegurem [...] o combate ao racismo, sexismo, homofobia, discriminação social, cultural, religiosa, prática de bullying [...], para o debate e a promoção da diversidade étnico-racial e de gênero, orientação sexual [...]" (p. 25); "Garantir, desenvolver e executar [...] políticas públicas [...] que visem à promoção da igualdade [...] de gênero [...] (p. 35); e "Inserir, implementar e garantir na política de valorização e formação inicial e continuada dos/as profissionais da educação a discussão de raça, etnia, gênero, identidade de gênero, diversidade sexual, religiosa 
[...]" (p. 36). Ao todo, localizamos 45 registros do termo "gênero" e mais 33 relacionados a "diversidade sexual" ou "orientação sexual".

Na sequência, o FNE e o MEC enviaram aos estados e municípios material orientativo sobre a elaboração dos planos de educação, incluindo o próprio documento-final da CONAE-2014. Isso causou forte reação aos grupos conservadores que haviam lutado pela retirada da "ideologia de gênero" do PNE. Indignados, passaram a denunciar que o MEC estava desobedecendo o próprio PNE. A guerra estava instaurada!

De ponto de vista legislativo, a reação se deu por meio da proposição de projetos de lei. Um deles, o PL n. 2.731/2015, de autoria do Dep. Eros Biondini, buscou alterar Lei que estabeleceu o PNE, para determinar que "É proibida a utilização de qualquer tipo de ideologia na educação nacional, em especial o uso da ideologia de gênero, orientação sexual, identidade de gênero e seus derivados, sob qualquer pretexto" (BRASIL, 2015a, p. 1) Propunha, ainda, que o descumprimento de tal proibição "[...] sujeitará os infratores às mesmas penas previstas no artigo 232 da Lei $\mathrm{n}^{\circ}$ 8.069/90 (ECA), além da perda do cargo ou emprego" (2015a, p. 2). Seu intento era de evitar que estados e municípios fossem "induzidos a erro" pelo Governo Federal, legislando "[...] irregularmente a ideologia de gênero em seus Planos de Educação", com vistas a "[...] proteger crianças e adolescente dos efeitos nocivos da Ideologia de Gênero" (BRASIL, 2015a, p. 9).

Uma segunda proposta foi formalizada pelo PL 3.236/2015, de autoria do Dep. Pastor Marco Feliciano, apresentando objetivos similares, pois pretendia insertar no PNE, a vedação de que, a "[...] se estimule a propagação da maléfica doutrina de gênero, por qualquer meio ou forma, em flagrante conflito com as convicções morais e religiosas dos educandos ou de seus pais ou responsáveis" (BRASIL, 2015b, p. 8).

Em função da polêmica instituída, a Secretaria de Educação Continuada, Alfabetização, Diversidade e Inclusão (SECADI/MEC) lançou a Nota Técnica ${ }^{\circ}{ }_{24}$, de 17 de agosto 2015, contendo explicações e orientações a respeito da importância de se incluir o conceito de gênero e orientação sexual no contexto educacional. O documento faz referências a pesquisas que indicam a existência de preconceito e discriminação no espaço escolar, acarretando, inclusive, baixo desempenho escolar e que, por isso, os conceitos de gênero e orientação sexual são fundamentais tanto para a garantia de direitos fundamentais, quanto para a qualificação do processo de ensino-aprendizagem. Por fim, a Nota reitera que tais conceitos decorrem de um "[...] conhecimento cientificamente produzido que não pode ser excluído do currículo" (BRASIL, 2015c, p. 5).

Com isso, o conflito político-discursivo eclodiu país a fora. De um lado, grupos religiosos e conservadores orquestraram diferentes estratégias para combater a 
chamada "ideologia de gênero" nos planos estaduais e municipais de educação. De outro, membros e representantes do movimento feminista e LGBTQ $+{ }^{2}$, defensores dos direitos humanos e educadores em geral também se articularam para defender a inclusão dos conceitos de gênero e orientação sexual nos documentos regionais. No município de Chapecó, Santa Catarina, essa disputa também ocorreu.

Face a isso, neste trabalho objetivamos narrar e analisar as disputas políticas travadas entre gênero e religião a partir da denominada "ideologia de gênero" na discussão da proposta do Plano Municipal de Educação (PME) de Chapecó/SC. Para isso, apresentamos algumas razões pelas quais os defensores da "ideologia de gênero" defendem seus posicionamentos relativos as questões de gênero e orientação sexual qualificando estes conceitos como algo destrutivos para a ordem estabelecida. Neste embate foi possível identificar tensas relações entre gênero e religião no contexto do Estado laico e na incessante busca pela promoção dos direitos humanos.

A partir de uma abordagem qualitativa, combinamos pesquisa do tipo bibliográfico com a observação in loco da audiência pública promovida pela Câmara Municipal de Chapecó para discutir o PME. Por fim, destacamos a complexidade que estes temas tem atualmente na sociedade, onde diversos grupos desenvolvem batalha político-ideológica a respeito desta questão, e indicamos que é imprescindível a criação de políticas de combate à violência e a desigualdade de gênero, inclusive no espaço escolar.

\section{A "ideologia de gênero" como propaganda discursiva}

Como vimos, o emprego da denominada "ideologia de gênero" foi o centro da disputa política durante a construção dos planos de educação em todo o país. Por isso, antes de retratar o caso de Chapecó, é importante esclarecer a origem desta expressão utilizada de maneira articulada por diferentes grupos, no intuito de empreender campanhas anti-gênero e atacar as conquistas dos movimentos feministas desde o campo político e religioso.

Um primeiro elemento a considerar é que a origem do movimento anti-gênero, atualmente presente em todos os países da América Latina, não é proveniente das bases populares, mas sim de uma trama política de agentes e instituições internacionais aliadas a plataformas religiosas, que conseguiu difundir em larga escala uma compreensão equivocada do que a academia convencionalmente conceitua por "gênero".

O conceito de gênero, segundo a Nota Técnica do MEC $n^{0}$ 24/2015, diz respeito à "[...] construção de práticas, representações e identidades que posicionam os sujeitos a partir de uma relação entre masculinidade e feminilidade" (BRASIL, 2015c, p. 1). Trata-se de um conceito fundamental para compreender a "[...] dimensão históri-

\begin{abstract}
2 Trata-se da versão atualizada da sigla LGBT que foi ampliada para incluir outros espectros de gênero e sexo. Cf. https://www1.folha.uol.com.br/mundo/2018/o6/sigla-lgbtq-cresce-para-ecoar-amplidao-do-espectro-de-genero-e-sexo.shtml. Acesso em 05 set. 2019.
\end{abstract}


ca, social, política e cultural das diferenças e do próprio processo de construção subjetiva de homens e mulheres" (2015c, p. 1). Assim, a noção de gênero possibilita analisar, evidenciar e problematizar as desigualdades entre homens e mulheres, propondo transformações sociais para garantir diretos fundamentais.

Compreensão, portanto, muito diferente daquela mobilizada pelos grupos conservadores e religiosos como propaganda discursiva. Como aponta Boehler (2018), os discursos anti-gênero estão atravessados por uma ideologia patriarcal sustentada por setores político-religiosos que entendem gênero como "libertinagem ou perversão", provedora do homossexualismo e, por conseguinte, contrária aos princípios cristãos e danosa à família tradicional.

A autora (2018), com base na pesquisa de Sonia Correa, afirma que o aparecimento da "ideologia de gênero" ocorreu no início do século XXI no seio de grupos diversos (conservadores, fundamentalistas ou fascistas) como uma forma de resistência e contra-ataque às conquistas do movimento feminista. Inicialmente, foi o Vaticano e os governos islâmicos quem manifestaram preocupações com o aparecimento do termo "gênero" e "sexualidade" nos documentos da ONU, geralmente relacionados aos direitos das mulheres, tais como saúde reprodutiva, justiça e equidade de tratamento na educação e no mercado de trabalho.

A preocupação dos agentes eclesiásticos decorre da suspeita de que tais temas estão "escapando" do controle religioso. Assim, começaram a obstaculizar a afirmação dos direitos das mulheres que, ao fim e ao cabo, acabam por desconstruir a histórica condição de serviçais, serventes e submissas para assumirem-se como pessoas capazes, inteligentes e em condições de ocupar espaços de poder, inclusive nas estruturas religiosas. Portanto, o conceito de "gênero" é uma ferramenta de análise que possibilita questionar, enfrentar e superar o poder hegemônico patriarcal e heteronormativo institucionalizado.

Ainda segundo Boehler (2018), na América Latina, alguns representantes e segmentos do movimento pentecostal e neopentecostal apropriaram-se genericamente do termo "ideologia de gênero" para torná-lo um elemento de propaganda discursiva de combate a demandas sociais tidas como "ameaçadoras" do Cristianismo, tais como: o direito ao aborto, a existência de famílias diversas ou homoparentais, a educação sexual e de gênero nas escolas, entre outros. Nas palavras da autora,

Si analizamos los discursos públicos que aparecen en los medios de prensa, contienen argumentos precarios, sin gran profundidad en su análisis, pero con gran alcance respecto de la masa poblacional de creyentes, a la que se apela con argumentos de sentido común y de una moral cerrada en lo relativa al modelo hegemónico de familia y de sexualidad. 
Argumentos que retumban en mentes poco informadas o estructuralmente formateadas desde una cultura patriarcal, y que afianza mentalidades poco críticas y naturalizan determinados roles y modelos atribuidos a lo que sería la especie humana. (BOEHLER, 2018, p. 10-11).

Como podemos deduzir, o problema está quando líderes religiosos buscam partidos políticos de linha conservadora e se colocam como defensores da moral - moral esta que muitas vezes não testemunham em sua vida pessoal - e, em nome disso, convencem contingentes populacionais que os projetam na vida política. Uma vez eleitos como vereadores, prefeitos, deputados, senadores e até presidentes, não se mostram preocupados em governar para o bem comum, mas sim em favor de seus interesses privados e confessionais.

Com isso, abre-se espaço para a prática proselitista na esfera pública, uma afronta a laicidade estatal, pois atuam na propagação de um único centro de verdade derivada de uma interpretação parcial da doutrina cristã. Não raro, a retórica proselitista opera na tentativa de silenciamento e repressão de outras formas de religiosidades, valendo-se até da prática de demonização do outro com o intuito de caracterizá-lo como inferior, subalterno, anormal ou exótico. Isso representa uma nítida apropriação da esfera pública (res publica) pelo mundo privado (res privata). Esse movimento é perigoso, porque algumas pautas exclusivistas atentam sobre o conjunto de valores públicos comuns que devem recair sobre todos indistintamente (CECCHETTI, 2019.)

Diante dessas problemáticas é imprescindível que o Estado seja laico para assegurar a liberdade de consciência e religião, assim como, para dar respostas aos dilemas com base no conjunto de valores públicos comuns. Cada vez mais, tais questões obrigam os Estados a mediarem com firmeza e imparcialidade as inúmeras pressões de confissões religiosas e a gama de reivindicações provenientes tanto de grupos maioritários, quanto de grupos excluídos ou em situação de vulnerabilidade social, com vistas a assegurar seus direitos.

$\mathrm{O}$ atual crescimento da hostilidade e do fundamentalismo, fomentados muitas vezes por grupos político-religiosos conservadores, expõe as fragilidades do regime de laicidade adotado pelo Brasil, por exemplo, uma vez que "Um Estado que não é imparcial, que protege e promove somente uma crença religiosa, não pode cumprir com seu papel de árbitro das diferenças ou de articulador do interesse comum" (BLANCARTE, 2008, p. 54)

Em um Estado laico, todos devem ter o direito de se expressar e influir nos rumos das políticas públicas, já que é um direito inerente ao regime democrático, mas isso exige que legisladores, dirigentes e funcionários públicos 
orientem seu trabalho para além da visão individual de mundo que compartilham, bem como, saibam superar as pressões e ditames dos grupos em disputa. Portanto, precisam resguardar o interesse público, mesmo que isso, às vezes, contrarie suas próprias convicções pessoais.

Entretanto, no atual cenário político brasileiro percebemos cotidianamente que muitos legisladores, ministros e governantes buscam construir sua legitimidade política por meio de alianças e apoios de determinados setores religiosos, o que acaba por fragilizar sobremaneira o caráter laico do Estado. Por outro lado, é cada vez mais visível a ação organizada de determinados segmentos religiosos com fins de eleger seus representantes em todos os níveis do poder público, para que coloquem em pauta seus interesses particulares.

Por essas razões, é evidente que a defesa da laicidade é central para garantia das liberdades e dos direitos individuais e coletivos. A esfera pública e as políticas do Estado não podem ficar à mercê das crenças e convicções exclusivistas, sejam religiosas, econômicas ou de outra natureza, porque coloca em risco a efetividade dos direitos e liberdades individuais e coletivas

\section{Embates entre gênero e religião no plano municipal de educação de Chapecó}

Os embates decorrentes da "ideologia de gênero" que emergiu em todo o Brasil também se repetiram no Legislativo chapecoense. Como vimos, o Plano Municipal de Educação (PME) apresenta metas e estratégias a serem implementadas no município de Chapecó por um período de 10 anos. Sua elaboração e tramitação incluiu o debate com a sociedade civil organizada juntamente com representantes de instituições governamentais tanto do poder legislativo como do executivo. Assim sendo, houve diferentes espaços e momentos em que este Plano entrou em debate. Contudo, nossa análise focaliza apenas a audiência pública realizada pela Câmara dos Vereadores no dia 31 de julho de 2015.

O PME deu entrada no Legislativo de Chapecó no dia 12 de junho e havia sido pauta de muitas discussões, principalmente em relação à presença do termo gênero em determinados trechos. Para tratar do tema, a Casa Legislativa criou uma Comissão para revisar a proposta do Plano apresentada pelo Executivo. Durante a tramitação, 23 emendas foram protocoladas ao projeto sugerindo modificações, sendo que apenas duas delas eram relativas ao tema de gênero.

Isso significa que questões de grande importância foram postas de lado por conta da disputa entre incluir ou não a palavra "gênero" nas diretrizes e metas estabelecidas no Plano. Vale lembrar que na audiência pública os setores da sociedade interessados poderiam manifestar suas considerações em relação a aprovação ou não das emendas sugeridas. 
Antes de tratarmos dos conteúdos dos debates é necessário fazer uma breve descrição do espaço e dos grupos que participaram deste evento, já que não é comum a participação popular de maneira tão significativa nos debates legislativos ordinários. Todavia, no dia 31 de julho de 2015, o plenário da Câmara de Vereadores ficou lotado. A quantidade de pessoas ultrapassou os lugares disponíveis para o público. Algumas pessoas ficaram em pé e outras não conseguiram entrar. Até senhas foram distribuídas para controlar o número máximo de pessoas.

No meio da multidão apareciam cartazes e faixas com diversas mensagens que representavam grupos diferentes: os que lutavam pela inclusão do conceito de gênero e os que rejeitavam esta possibilidade. Assim os conteúdos que apareceram identificavam essas diferenças, tais como: "menino nasce menino e menina nasce menina", "NÃO a ideologia de gênero, NÃO a lavagem cerebral em nossos filhos”. As outras posições expressavam: "o estado é laico"; "queremos uma educação que não promova mais opressão"; "católicas pelo direito de decidir é a favor dos estudos de gênero no PME"; "respeito a Constituição, não a opressão e sem fundamentalismos".

Geograficamente, o plenário ficou claramente dividido: de um lado estavam aqueles que apoiavam a retirada de qualquer referência ao termo "gênero", por identificá-lo como decorrente da "ideologia de gênero". Em sua grande maioria, tal grupo composto por lideranças e adeptos de Igrejas cristãs, incluindo a presença de um pastor pentecostal que veio de Minas Gerais para participar do evento, assim como, do bispo católico da Diocese de Chapecó. Ambos tiveram oportunidade de falar e defender seus posicionamentos pelo cargo hierárquico que ocupam na sociedade.

De outra parte, estavam os defensores da inclusão do conceito de gênero no Projeto, constituídos por representantes do movimento LGBTQ+, professores e estudantes de universidades e de escolas municipais e estaduais, além do Sindicato que representa esta categoria profissional.

Após apresentação do Plano e das ementas sugeridas, fizeram uso da palavra a Secretária Municipal de Educação; o representante da Ordem dos Advogados do Brasil (OAB - subseção de Chapecó); representantes das universidades federal e comunitária; representante do sindicato dos professores e alguns dos vereadores do município.

O mesmo conflito revelado nos cartazes foi expresso nos posicionamentos da mesa. A secretária municipal de educação foi taxativa ao declarar que a igualdade de gênero já está compreendida dentro do texto original e que as estratégias devem ser definidas posteriormente, assim "não precisa colocar a palavra gênero no plano municipal". Cinco vereadores manifestaram-se claramente contra as emendas objetivando a "defesa da família" e que a prerrogativa de ensinar sobre gênero é dos pais. No entanto, um deles com mais ímpeto, dirigindo-se ao movimento 
LGBT ali presente, afirmou: "a minoria não me importa, vou votar contra e vou fazer campanha contra”. (DIÁRIO DO IGUAÇU, 2015).

Por sua vez, o representa da OAB se posicionou acerca da importância da inclusão de gênero no PME, argumentando que "educar para o respeito às mulheres, a diversidade sexual, a identidade de gênero é tão importante quanto inibir o racismo e promover a liberdade religiosa". Na mesma direção, uma pesquisadora universitária enfatizou que a categoria "gênero" é útil para a compreensão das relações nas famílias, nas escolas e na sociedade como um todo. Essa compreensão, permite diminuir as desigualdades de gênero que geram tanta violência. Também enfatizou a compreensão das diferenças entre ciência e religião e a necessidade de respeitar o Estado laico, motivo pelo qual a educação nas escolas não pode ser orientada por dogmas religiosos.

A despeito da insistência do Presidente da Casa em afirmar que em nenhuma linha do PME constava a expressão "ideologia de gênero", ao longo de toda a audiência se debateu o perigo da "ideologia de gênero" e os significados sobre o que seria realmente a categoria gênero. Entre os conteúdos atribuídos a "ideologia de gênero" expressos na audiência pública, principalmente nas falas dos vereadores, estavam: a defesa da família tradicional - aquela constituída por homem e mulher - ; defesa de que os pais são os responsáveis pela formação das crianças e não as escolas; que as pessoas já nascem homem ou mulher, diferenciados pelo seu sexo biológico sem possibilidade de variação. Assim, aceitar a "ideologia de gênero" nas escolas é acabar com todos os valores e práticas sociais que embasam o modelo de instituições sociais ancoradas nestes princípios.

Conforme tratamos anteriormente, a expressão "ideologia de gênero" é equiparada por estes grupos à categoria de análise "relações de gênero", construída pelas ciências humanas, que busca compreender como ocorrem as relações entre gêneros. Os estudos sobre gênero têm contribuído para que as pessoas conheçam a si mesmas, compreendam seu corpo, seu mundo, sua identidade e saibam respeitar ao outro, ao diferente.

Contudo, a falta de compreensão por parte dos grupos conservadores, que se organiza em nível nacional, estadual e municipal, impede que este debate integre conteúdos e práticas pedagógicas na formação escolar. Segundo o posicionamento do MEC, as escolas participam

[...] ativamente na construção dos corpos e identidades dos sujeitos da educação, especialmente, das suas e dos seus estudantes. Obviamente as escolas brasileiras não têm um único jeito de ensinar sobre gênero e sexualidade, mas pesquisas evidenciam currículos e práticas pedagógicas e de gestão marcados pelo sexismo, pela misoginia e pela 
discriminação dos sujeitos não-heterossexuais ou que descumprem expectativas hegemônicas de gênero. (BRASIL, 2015c, p. 2).

Distantes de uma compreensão pedagógica, grupos conservadores provenientes de diferentes Igrejas cristãs acreditam que somente a sua Teologia resguarda um código de ética válido, incluindo as prerrogativas aceitáveis no que se refere ao exercício da sexualidade e das atividades humanas reprodutivas. Assim, por exemplo, a homossexualidade é vista como doença, desvio; a diversidade é concebida como grave perigo que põe em risco a organização social.

Tem-se, então, uma contradição de ordem ética entre os que desejam impor uma determinada ética baseada em verdades religiosas em uma sociedade diversa, regida por um Estado laico, e os que defendem um Estado e uma ética independente da crença religiosa.

O Estado laico não é uma instituição política neutra com relação a valores. Ele se acha vinculado a componentes essenciais da coexistência social como a tolerância, o respeito à diversidade religiosa, a separação Igreja e Estado, a liberdade de consciência, a democracia e mesmo à própria liberdade religiosa.

O questionamento quanto ao alcance do Estado laico torna-se, portanto, uma séria ameaça às liberdades civis. Essas liberdades, em muitos casos, conseguidas a duras penas, são ameaçadas pelo que tem sido denominado como "recolonização da esfera pública" pelas religiões institucionalizadas. Nesse caso, acontece o que Bobbio (1986) entende como subordinação da política aos dogmas da religião dominante e, consequentemente, a subordinação dos princípios éticos das demais religiões presentes no Estado, impedindo o exercício da legítima liberdade religiosa.

Discutir as questões de gênero problematiza o determinismo biológico, gerando possibilidades de desconstrução das ideias naturalizadas do que é ser homem e do que é ser mulher, a partir da percepção sobre a construção cultural e social destas identidades. O uso analítico da categoria de gênero, nos estudos sobre sexualidade e reprodução, aplicada em diversos contextos históricos e culturais, tem sido um instrumento teórico que trouxe inúmeras implicações analíticas e políticas, como assinala Barbieri:

O poder contido nos sistemas de gênero opera, com mais força, nos estágios reprodutivos da vida humana, quando os meios para controlar a sexualidade, a reprodução e o acesso às atividades produtivas estão situadas e funcionam de maneira mais aguda. Esta definição favorece a desconstrução das diferenças de gênero que foram e continuam sendo interpretadas, racionalizadas como resultado de uma ordem natural e biológica imutável, no sentido de pensá-las como circunstâncias 
construídas social e historicamente e, portanto, sujeitas à transformação pela ação social e política. Esta compreensão do gênero como um operador social simbólico, também possibilita o exame das relações de poder inter e intragêneros (BARBIERI, apud CORREA, 1996, p.150).

Família, sexualidade, reprodução e religião, mais do que entidades possuidoras de uma natureza particular, constituem, para a abordagem sócio antropológica, dimensões da vida coletiva que distinguem sistemas sociais. São redes de relações que envolvem múltiplos aspectos, tais como a reprodução biológica e social, encontros sexuais e sociabilidade, crenças e rituais entre outros. (HEILBORN et al, 2005) Todos estes constructos da vida social estão permeados pela cultura ocidental cristã que orienta a constituição dos sujeitos e os modos de vida.

\section{Considerações Finais}

Cotidianamente, diferentes pesquisas e estatísticas indicam que meninas, mulheres e toda a população LGBTQ+ são vítimas de discriminação e sofrem diferentes tipos de abusos, exploração, desigualdades e violências decorrentes de crimes de ódio (racismo, feminicídio e homofobia), tal como retrata Souza (2018).

No campo educacional, a desigualdade de gênero e a homofobia impõem muitas barreiras em termos de acesso, permanência, conclusão dos estudos, o que resulta em desvantagens na vida social e profissional. A presença de estereótipos de gênero nos currículos, livros didáticos e processos de ensino, a violência que enfrentam dentro e fora da escola, restrições estruturais e ideológicas e a dominação masculina em determinados campos acadêmicos e profissionais são fatores que impedem obstaculizam o direito humano à educação em condições de igualdade.

Por isso, instituições e movimentos que militam pela promoção dos direitos humanos defendem a necessidade de o Estado promulgar leis e criar políticas de combate a violência e a desigualdade de gênero. Assim, é imprescindível que os espaços educativos promovam uma educação inclusiva, combatendo toda e qualquer forma de discriminação.

Neste intento, consideramos fundamental problematizar a denominada "ideologia de gênero", mobilizada e defendida por setores significativos da sociedade como instituições religiosas, movimentos, grupos de diversas classes sociais e lideranças políticas que se manifestam de forma enfática em diferentes espaços públicos para mostrar o quão perniciosa é a questão de gênero, como foi expressada na audiência pública narrada neste trabalho.

Quando nas diretrizes de um PME se inclui a questão de gênero como algo importante para o currículo escolar, surgem diversas interpretações a respeito do que 
significa esta inclusão. De fato, entram em disputas paradigmas divergentes relativos aos conceitos de gênero e orientação sexual. De um lado um paradigma sustentado em valores religiosos, sobretudo cristãos, no qual o determinismo biológico passa a ser o critério central para as relações humanas, para a compreensão do ser homem e do ser mulher, da sexualidade, da reprodução e da família. De outro lado aquele construído na visão social e histórica sujeito a transformações pela ação social e política sem excluir a dimensão biológica.

Controle sobre o corpo, sexualidade e reprodução historicamente tem se constituído como um dos pilares de várias religiões. No Cristianismo isso se evidencia através das concepções sobre matrimonio, maternidade, família, reservando lugares específicos para as mulheres e os homens, onde as diferenças biológicas determinam hierarquização das identidades e o pertencimento a esfera pública e privada.

Contudo nas últimas décadas, o debate sobre as questões de gênero tem buscado promover valores democráticos, tais como a liberdade e o respeito às diferenças, tão necessárias para a convivência em sociedades diversas como as contemporâneas.

Todos os embates e disputas entre as questões de gênero e religião revelam que a igualdade de gênero ainda está longe de ser realizada plenamente, e que a mudança desse cenário depende de uma mudança de mentalidade, o que só se tornará possível por meio do conhecimento e reflexão crítica sobre a realidade - ações estratégicas que escola não pode se furtar ou ser impedida de fazer.

\section{Referências}

BLANCARTE, R. J. Para entender el estado laico. México: Nostra Ediciones, 2008.

\section{BOBBIO, Norberto. Sociedade e Estado na filosofia} política moderna. São Paulo: Editora Brasiliense, 1991.

BRASIL. Ministério da Educação. Documento final. Conferência nacional de educação 2010. Construindo o sistema nacional articulado de educação. O plano nacional de educação, diretrizes e estratégias de ação. Brasília: MEC, 2010a.

BRASIL. Projeto de Lei n. 8.o35, de 20 dezembro 2010b. Aprova o plano nacional de educação para o decênio 2011-2020 e dá outras providências. Disponível em: https://www.camara.leg.br/proposicoesWeb/prop_ mostrarintegra?codteor $=831421$. Acesso em 5 set. 2019 .

BRASIL. Lei n 13.005, de 25 de junho de 2014a. Aprova o Plano Nacional de Educação - PNE e dá outras providências. Disponível em: http://www.planalto.gov.br/ 
ccivil_03/_Ato2011-2014/2014/Lei/L13005.htm. Acesso em: em 5 set. 2019.

BRASIL. Fórum Nacional de Educação. Documento final. Conferência nacional de educação 2014. Brasília: FNE, 2014b.

BRASIL. Câmara dos Deputados. Projeto de lei no 2.731 de 2015a (Do Sr. Eros Biondini) Altera a Lei $n^{0}$ 13.005, de 25 de junho de 2014, que "Aprova o Plano Nacional de Educação - PNE e dá outras providências”. Disponível em: https://www.camara.leg.br/proposicoesWeb/prop_ mostrarintegra?codteor $=1374936$. Acesso em: em 5 set. 2019.

BRASIL. Câmara dos Deputados. Projeto de lei no $\mathbf{3 . 2 3 6}$ de 2015b (Do Sr. Marco Feliciano). Acrescenta parágrafo único ao artigo $2^{\circ}$ da Lei $n^{\circ} 13.005$, de 25 de junho de

2014, que "Aprova o Plano Nacional de Educação - PNE e dá outras providências”. Disponível em: https://www. camara.leg.br/proposicoesWeb/prop_mostrarintegra?cod teor $=1397230 \&$ filename $=P L+3236 / 2015$. Acesso em: em 5 set. 2019.

BRASIL. Ministério da Educação. Secretaria de Educação Continuada, Alfabetização, Diversidade e Inclusão. Nota Técnica no 24, de 17 de agosto 2015c. Disponível em: http://www.educadores.diaadia.pr.gov.br/arquivos/File/ pdf/nota_tecnica242015_mec.pdf. Acesso em: em 5 set. 2019.

BRITTO, T. F. de. Passo a passo no legislativo: os caminhos do plano nacional de educação no congresso nacional. In: GOMES, A. V. A; BRITO, T. F. de. (Orgs.). Plano nacional de educação: construção e perspectivas. Brasília: Câmara dos Deputados, Edições Câmara: Senado Federal, Edições Técnicas, 2015 [recurso eletrônico].

BOEHLER, G. Teorías, teologías, género e ideologías. Vida y pensamiento-UBL, v. 38 (1), p. 1-32, Ene-Jun 2018.

CAVALCANTE, J. M.; et al. Discursos políticos acerca da "ideologia de gênero" na discussão do plano municipal de educação de João Pessoa-PB. Interfaces Científicas Educação, v.5, n.3, p. 17-30, jun. 2017.

CECCHETTI, E. Estado laico e seu estatuto jurídico. In: TORRES, E. O (Ed). Las paradojas de la libertad religiosa en América Latina. Santiago: GEMRIP, 2019.

CORREA, S. Gênero e sexualidade como sistemas autônomos: ideais fora do Lugar? In: PARKER, R.; BARBOSA, R. M. (Org) Sexualidades brasileiras. Rio de Janeiro: Relume Dumará: ABIA: IMS/UERJ, 1996, p. $149-159$. 
DIÁRIO DO IGUAÇÚ. Plano Municipal de Educação. Câmara Discute gênero no PME. Chapecó. 01 e 02 de agosto de 2015 .

HEILBORN, M. L.; et al. (Org.). Sexualidade, família e ethos religioso. Rio de Janeiro: Garamond, 2005.

SOUZA, R. C. A. F. de. Crimes de ódio: racismo, feminicídio e homofobia. Belo Horizonte: Editora D’Plácido, 2018.

Recebido em: 20/08/2019 Aprovado em: 06/12/2019 Publicado em: 20/12/2019 